\title{
HUMAN CYTOMEGALOVIRUS LOAD IN THE PERIPHERAL BLOOD DETERMINED BY QUANTITATIVE COMPETITIVE POLYMERASE CHAIN REACTION*
}

\author{
KRISZTINA SZŐKE, GYÖRGYI SZLÁDEK, KRISZTINA SZARKA, ATTILA JUHÁSZ, \\ GYÖRGY VERESS, LAJOS GERGELY AND JÓZSEF KÓNYA** \\ Institute of Microbiology, Medical Faculty, Medical and Health Science Center, \\ University of Debrecen, Debrecen, Hungary \\ Mailing address: P.O. Box 17, H-4012 Debrecen, Hungary \\ E-mail: konya@jaguar.dote.hu
}

(Received: March 14, 2001; accepted: April 18, 2001)

\begin{abstract}
Primary human cytomegalovirus infection and the viral reactivation from latency are major complications in organ transplant recipients. In the peripheral blood the replicating virus can be detected either by nucleic acid based tests or by demonstrating the HCMV structural proteins in antigenemia test. We developed a quantitative competitive PCR method to assess the HCMV load in the peripheral blood. The viral load in nine healthy blood donors and in four renal transplant recipients with negative antigenemia test was in the same range: 5-124 (median: 18) HCMV copies $/ 10^{6} \beta$-globin copies for healthy blood donors and 16-48 (median: 37) HCMV copies $/ 10^{6} \beta$-globin copies for the transplant recipients. Three antigenemia positive renal transplant recipients had a HCMV load of $2,2 \times 10^{5} / 10^{6} \beta$-globin, $1,5 \times 10^{4} / 10^{6} \beta$-globin and $6,5 \times 10^{3} / 10^{6} \beta$-globin, respectively. In conclusion, the quantitative measurement of HCMV load in the peripheral blood correlated well with the routine HCMV antigenemia test. The DNA-based test, however can detect earlier the reactivation of the HCMV infection.
\end{abstract}

Keywords: cytomegalovirus, renal transplant recipients, quantitative PCR

\footnotetext{
* This paper was written to commemorate to the fiftieth anniversary of the foundation of the Hungarian Society for Microbiology.

** Corresponding author
} 


\section{Introduction}

Primary human cytomegalovirus (HCMV) infection and the viral reactivation from latency are major complications in organ transplant recipients. After the primary infection, the virus establishes a latent infection in certain cell types like monocytes and $\mathrm{CD} 34+$ bone marrow cells $[1,2]$. During the latent stage, the number of mononuclear cells carrying the virus is extremely low (about 1/10,000) in the peripheral blood [3] and the HCMV DNA can be detected neither in the polymorphonuclear leukocytes (PMNLs) nor in the plasma [1, 4, 5]. Regarding viral expression during latency, only the immediate early (IE) region is transcribed at a reduced rate [4]. The differentiation of monocytes into tissue macrophages enables the lytic gene expression of HCMV and the release of infectious virions. However the cells expressing the lytic genes of HCMV are controlled by the HCMV specific cytotoxic Tlymphocytes in the immunocompetent host [6]. Thus, immunosuppression is a risk factor for the HCMV viraemia and the HCMV diseases. During the viraemic phase, the complete viral expression is detected in the peripheral blood mononuclear cells [7, 8]. The polymorphonuclear cells may take up the virus and may reveal even the expression of the IE region [9]. The diagnosis of acute HCMV infection is based on the demonstration of virus replication. Detection of anti-HCMV IgM type antibodies in organ transplant recipients has a limited diagnostic value, because active HCMV infection can become fatal even before the IgM type antibodies appear. The HCMV antigenemia test demonstrates the presence of the pp65 tegument protein in the circulating leukocytes. The pp65 is the most abundantly produced viral protein in early and late phases of the viral replication. Since the viral genome can be detected in low copy number in the latent phase of the infection, DNA based detection of HCMV viraemia from clinical samples containing mononuclear cells (e.g. whole blood) requires quantitative measurement of the viral load [10]. Alternative methods to examine the virus reactivation are the detection of early-late mRNA expression [11] and detection of viral genome in the plasma phase [12]. We developed a quantitative competitive PCR method using mutant sequences of extended length as internal controls. The results obtained by this methodology from peripheral blood samples of renal transplant patients correlated well with those of the pp65 antigenemia test. 


\section{Materials and methods}

\section{Cell cultures and clinical samples}

Human fibroblast cells were grown in DMEM $+5 \%$ fetal calf serum and were infected with human cytomegalovirus (strain $\mathrm{AD} 169$ ) at a multiplicity of infection 1. Infected cells were grown until $50 \%$ of the cells revealed cytopathic effect. The infected and mock-infected human fibroblast cells were harvested and resuspended in 2 ml TNE (10 mM Tris, $100 \mathrm{mM} \mathrm{NaCl}, 1 \mathrm{mM}$ EDTA) for DNA extraction. The study group consisted of seven renal transplant recipients and nine healthy blood-donors. Peripheral blood samples of the renal transplant recipients were tested for HCMV pp65 antigenemia with CINAkit Rapid Antigenemia test (Argene Biosoft, Varilhes France). Leukocytes for both the antigenemia and the PCR testing were isolated from 1,5 ml heparinized blood by lysing erythrocytes in eight volumes ice-cold lysis solution $\left(0.085 \% \mathrm{NH}_{4} \mathrm{Cl}\right)$. After washing once more in the lysis solution, $4 \times 10^{5}$ leukocytes were used for the antigenemia test according to the manufacturer's instructions, while the rest was processed for PCR amplification as follows: The leukocytes were washed once in PBS and resuspended in $2 \mathrm{ml}$ TNE for DNA extraction. DNA was isolated by phenol extraction and ethanol precipitation and resuspended in $50 \mu \mathrm{l}$ TE $(10 \mathrm{mM}$ Tris $\mathrm{pH} 8.0$, 0.1 mM EDTA).

\section{Competitive PCR}

HCMV-specific amplification was done by gB1 (5'gaggacaacgaaatcetgttgcgca $\left.3^{\prime}\right)$ and gB2 (5'gtcgacggtggagatactgctgagg 3') primers [9], the PCR cycle profile for HCMV was $95^{\circ} \mathrm{C} 30$ seconds- $-62^{\circ} \mathrm{C} 1$ minute $-72^{\circ} \mathrm{C} 1$ minute over 35 cycles. $\beta$-globin sequences were amplified by pCO3 (5'acacaactgtgttcactagc $3^{\prime}$ ) and pCO4 (5'caacttcatccacgttcacc $3^{\prime}$ ) primers [12]. The PCR cycle profile for $\beta$-globin was $95^{\circ} \mathrm{C}$ 30 seconds $-62^{\circ} \mathrm{C} \quad 1$ minute $-72^{\circ} \mathrm{C} \quad 1$ minute 30 seconds over 35 cycles. All PCR amplifications were done at a $\mathrm{MgCl}_{2}$ concentration of $1,5 \mathrm{mM}$ unless otherwise indicated. PCR products were excised and purified from low melting point agarose (2\%) with QIAquik Gel Extraction Kit (Qiagen GmbH, Hilden, Germany). The purified amplicons were cloned into pGEM-T Easy PCR cloning vector (Promega Corporation, Madison, USA). Recombinant plasmids were transfected into E. coli strain XL-1 as described by Chung et al. [13]. Recombinant colonies were screened by PCR amplification as follows: A pinhead amount of a colony was transferred into the PCR reaction mixture. The initial denaturation was three minutes long to promote the release and amplification of the plasmid DNA from the bacterial cell. PCR positive colonies were grown in large scale and plasmids were isolated with Wizard Plus Midipreps DNA Purification System (Promega, Madison, USA). The pgB (HCMV) 
plasmid was further modified inserting random $M b o \mathrm{I}$ fragments of human fibroblast genomic DNA into the BglII site. For the quantitative competitive PCR, the competitor plasmids of extended lengths were added to the PCR reaction. The PCR products were subjected to an electrophoresis in $1.5 \%$ agarose gel and stained with ethidium-bromide. The density of the wild band was compared with the density of the mutant band with Gel Doc 2000 Gel Documentation system (Bio RAD Laboratories Hercules, C. USA) as follows: a calibration curve was set by plotting log (calibrating copy number) against $\log$ ( [band density of wild type amplicon] / [band density of wild type + band density of competing amplicon] ).

\section{Results}

\section{Cloning competitive mutant sequences}

A 150 bp sequence of the glycoprotein B gene (gB) was amplified from human fibroblast cells infected with human cytomegalovirus (HCMV strain AD 169) and was cloned into pGEM T-Easy PCR cloning vector. Recombinant plasmid (pgB) was isolated in large scale from two recombinant colonies. The sensitivity limit of the PCR amplification was $10^{3}$ copies using any of the two pgB isolates. To increase the insert size of the $\mathrm{pgB}$ plasmid, we ligated random $\mathrm{MboI}$ fragments of human fibroblast genomic DNA into the unique $B g / I I$ restriction site of the $g B$ amplicon. Approximately twenty recombinant colonies were PCR amplified with HCMV primers (Fig. 1). Two recombinant colonies with about 350 (pgBm1) and 400 (pgBm5) bp insert, respectively, were selected for large-scale plasmid preparation. The sensitivity limit of the PCR amplification of the mutant sequences of extended length was $10^{3}$ copies.

A $110 \mathrm{bp}$ sequence of the $\beta$-globin gene was amplified from human fibroblast cells and was cloned into pGEM T-Easy PCR cloning vector. Recombinant plasmid $(\mathrm{pFB})$ was isolated in large scale from two recombinant colonies. The sensitivity limit of the PCR amplification was $10^{3}$ copies using any of the two (pFB1 and pFB2) isolates. The $\beta$-globin mutant sequence was amplified from human fibroblast genome by increasing the $\mathrm{MgCl}_{2}$ concentration. Aspecific bands appeared at a $\mathrm{MgCl}_{2}$ concentration of $6 \mathrm{mM}$ (Fig.2 lane 1). The aspecific bands were excised and extracted from the agarose gel and reamplified in two consecutive PCR amplifications (Fig.2 lanes $2,5,6,7)$. A $400 \mathrm{bp}$ aspecific fragment apparently flanked by the $\beta$-globin primer sequences was cloned into pGEM T-Easy PCR cloning vector. Recombinant plasmids $(\mathrm{pFBm} 1 ; \mathrm{pFBm} 2)$ were isolated in large scale from two recombinant colonies. The sensitivity limit of the PCR amplification was $10^{3}$ copies using any of the two plasmids. 


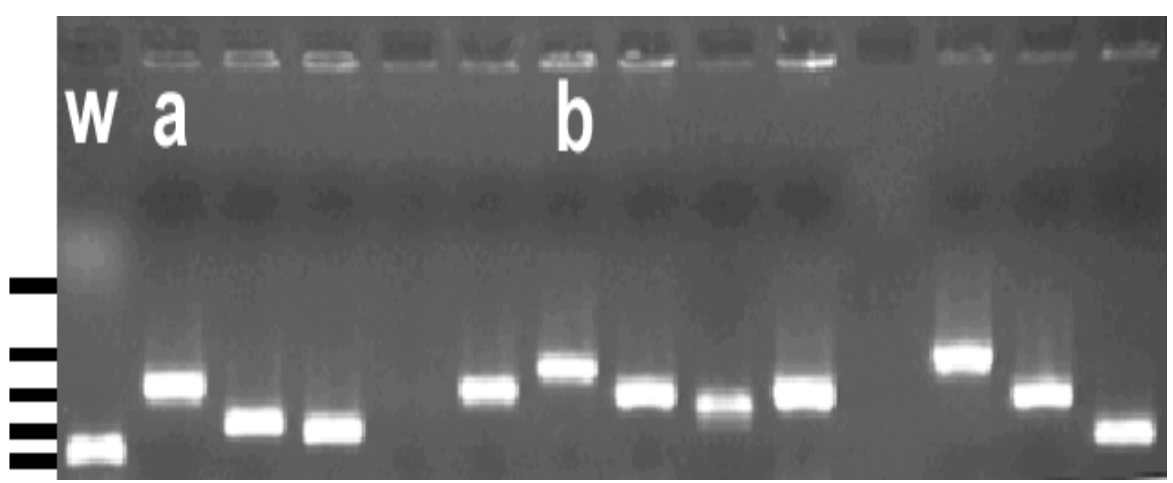

Fig. 1. Colony PCR after inserting random DNA fragments into the cloned 150 bp glycoprotein B sequence (pgB), (w) wild type pgB control (150 bp), (a, b) recombinant plasmids (pgBm1: $350 \mathrm{bp}, \mathrm{pgBm}$ : $400 \mathrm{bp}$ ) used for competitive PCR. Marker bands are 500, 400, 300, 200 and $100 \mathrm{bp}$ long
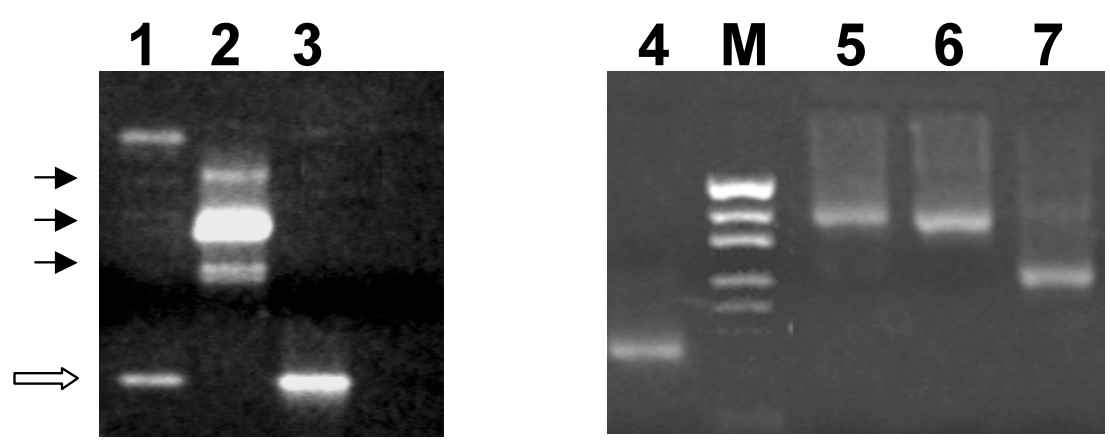

Fig. 2. Amplification of wild type and mutant $\beta$-globin sequences. White arrow indicates a $110 \mathrm{bp}$ sequence of the $\beta$-globin gene amplified from human fibroblast cells. Black arrows indicate aspecific PCR products at $6 \mathrm{mM} \mathrm{MgCl}_{2}$ concentration (lane 1). The aspecific PCR products are reamplified (lane 2). The $110 \mathrm{bp} \mathrm{long}$ sequence is reamplified (lane 3 ). Further reamplification of the wild type (110 bp) sequence (lane 4$)$ and the aspecific bands (lanes 5-7). Marker bands are 500, 400, 330, 240, 190, 150, 110 and 70 bp long (M)

\section{Competitive PCR}

The quantitative PCR method was based on the competition of templates. The lengths of the natural genomic fragments flanked by the primer sequences were $150 \mathrm{bp}$ and $110 \mathrm{bp}$ for the human cytomegalovirus (HCMV) and for the $\beta$-globin, respectively. The cloned mutant sequences of extended lengths (pgBm1, pgBm5, pFBm1, pFBm2) 
were used as competitors in the quantitative PCR. Serial dilutions of the recombinant wild type clones (pgB, pFB) were used to set the calibration curve (Fig. 3). For human cytomegalovirus (HCMV), the amount of the competitor necessary for one PCR amplification was optimized and $10^{3}$ competitor copies were found to provide a good quantitative estimation of the wild type sequences in the range of $10^{2}-10^{6}$. This range was expected to cover the number of the HCMV genomes to be detected. For $\beta$-globin, $5 \times 10^{5}$ competitor copies were found to provide a good quantitative estimation of the wild type sequences in the range of $10^{3}-10^{8}$, covering the expected number of the $\beta$ globin target sequences (Fig.3). We performed the calibration in every series of PCR amplification. The HCMV copy number was related to the number of $\beta$-globin copies. $\beta$-globin band intensities were rather uniform indicating that the applied DNA isolation method was reproducible.

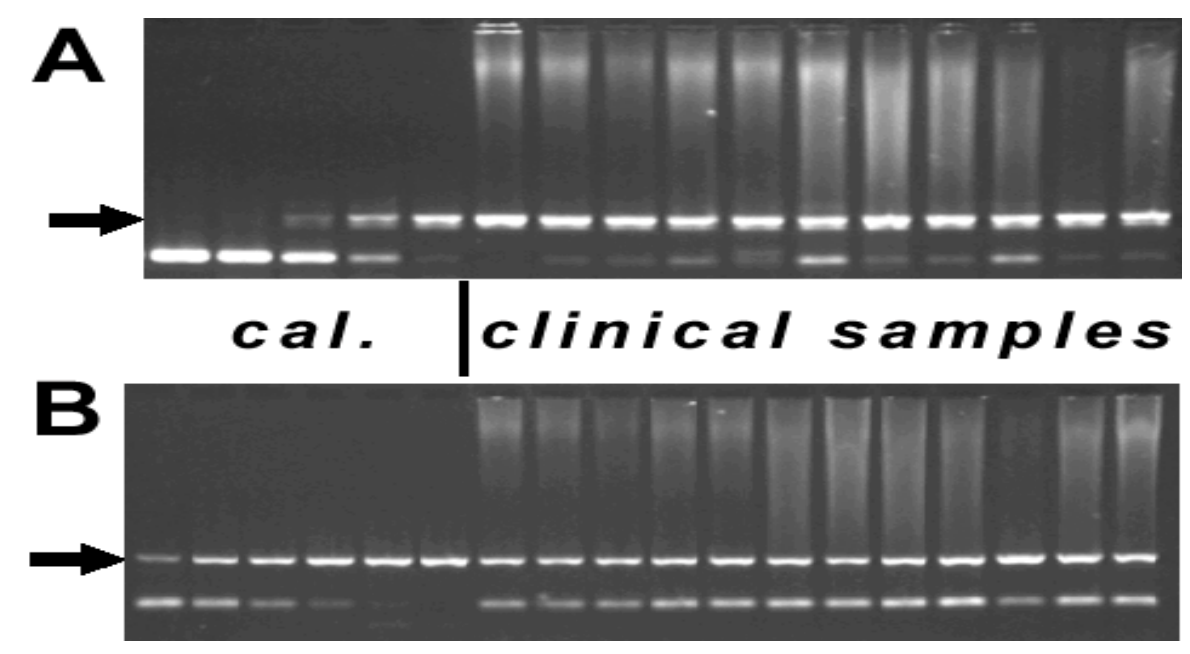

Fig. 3. Competitive PCR test of clinical samples. Arrows indicate the competitor bands. (A) HCMV amplification, $10^{3}$ competitor target copies/reaction, (cal.) calibrating series: $10^{6}-10^{2}$ copies/reaction. (B) $\beta$-globin amplification, $5 \times 10^{5}$ competitor target copies/reaction, (cal.) calibrating series: $10^{8}-10^{3}$ copies/reaction

The system was tested on the blood samples of nine healthy blood-donors and seven renal transplant recipients (Fig. 3). In case of healthy blood donors ( 9 donors), the HCMV load ranged from 5 to $124 / 10^{6} \beta$-globin copy (median: $18 / 10^{6}$ ). Four renal transplant patients who were negative by antigenemia test had 16-48 HCMV copies / $10^{6} \beta$-globin copies (median: 37 ) i.e. the HCMV load of the healthy blood 
donors and the antigenemia negative renal transplant patients tended to be in the same range. Three renal transplant recipients positive in antigenemia test had indeed high HCMV load in the peripheral blood. Patient \#1 with 30 antigenemia positive cells / $2 \times 10^{5}$ leukocytes had an HCMV load of $2.2 \times 10^{5} / 10^{6} \beta$-globin copies, patient \#2 with more than 100 antigenemia positive cells $/ 2 \times 10^{5}$ leukocytes had an HCMV load of $1.5 \times 10^{4} / 10^{6} \beta$-globin copies and patient $\# 3$ with 45 antigenemia positive cells / $2 \times 10^{5}$ leukocytes had an HCMV load of $6.5 \times 10^{3} / 10^{6} \beta$-globin copies. It is of interest that the positive PCR result of the patient $\# 2$ was detected 20 days before his positive antigenemia test indicating that DNA-based detection of HCMV replication can detect the reactivation of the virus infection earlier than the routinely used antigenemia test.

\section{Discussion}

Human cytomegalovirus (HCMV) infection can cause acute life-threatening disease in organ transplant recipients. We have developed a competitive PCR method to detect HCMV reactivation in renal transplant recipients. To produce mutant sequences of extended lengths, we changed $\mathrm{MgCl}_{2}$ concentration and the annealing temperature. For $\beta$-globin, the increase of $\mathrm{MgCl}_{2}$ concentration made it possible to amplify longer aspecific PCR products carrying the primer sequences at the ends, while lowering the annealing temperature did not result in aspecific longer bands. With the $\mathrm{HCMV} \mathrm{gB}$ primers, however, changing either the $\mathrm{MgCl}_{2}$ concentration or the annealing temperature did not result in aspecific amplicons. The other attempt was to introduce an $H p a$ I restriction site into the wild type $\mathrm{gB}$ sequence with PCR mutagenesis as described by Fox et al. [10]. Although this method worked well and provided reproducible measurements in competitive PCR, it required an extra restriction enzyme cleavage step after the PCR amplification, and the HpaI restriction fragments (75 bp) could be distinguished only in special agarose gels of high concentration (3-4\%). The occurrence of a unique BglII site in the wild type gB sequence was optimal to increase the size of the cloned sequence by inserting additional DNA fragments, which were produced with the isoschizomer MboI. In contrast to the $6 \mathrm{bp}$ recognition site of $B g l \mathrm{II}$, $\mathrm{MboI}$ recognizes only 4 base pairs, and thereby cleaves shorter random fragments. Eventually, we selected two mutant plasmids, where the insert was extended approximately by $200 \mathrm{bp}$ and $250 \mathrm{bp}$, respectively.

There were marked differences in length between the competing and wild type sequences. Supposing that the target copies are amplified at a rate equal or very similar to each other, the longer PCR product will yield a larger amount and a stronger intensity i.e. the density ratio between the bands of different length does not apply to 
the ratio between the competing and wild type sequence copies. Therefore calibration was done with a dilution series of cloned wild type target sequences, and this calibration was run in every PCR amplification in order to rule out any variation between the individual experiments.

We examined blood samples from healthy blood-donors and renal transplant recipients. According to our experiences, the amount of blood used to isolate DNA was critical. When only $200 \mu \mathrm{l}$ blood was processed with commercially available DNA isolation kits, the PCR signals were inconsistent in the healthy blood donors [3]. Therefore leukocytes were isolated from $1.5 \mathrm{ml}$ blood by lysing the red blood cells and then the DNA was phenol extracted from the leukocytes. Approximately one tenth of the isolated DNA was tested in a PCR reaction. This amount of DNA sample was found sufficient to amplify HCMV in a consistent manner. In conclusion, the quantitative measurement of HCMV load in the peripheral blood correlated well with the routine HCMV antigenemia test. The DNA-based test, however can detect earlier the reactivation of the HCMV infection.

Acknowledgements. This study was supported by grants from the Hungarian National Scientific Research Fund (OTKA T031953 and F034796), the Health Science Council (ETT 015/2000), and the Higher Education Research and Development Fund (FKFP 0292/2000).

\section{References}

1. Taylor-Wiedeman,J., Sissons,J.G., Borysiewicz,L.K., Sinclair,J.H.: Monocytes are a major site of persistence of human cytomegalovirus in peripheral blood mononuclear cells. J Gen Virol 72, 2059 (1991).

2. Sindre,H., Tjoonnfjord,G.E:, Rollag,H., Ranneber-Nilsen,T., Veiby,O.P., Beck,S., Degre,M., Hestdal,K.: Human cytomegalovirus suppression of and latency in early hematopoietic progenitor cells. Blood 88, 4526 (1996)

3. Urushibar,N., Kwon,K.W., Takahashi,T.A., Sekiguchi,S.: HCMV DNA is not detectable with nested double polymerase chain reaction in healthy blood donors. Vox Sang 68, 9 (1995).

4. Schrier,R.D., Nelson,J.A., Oldstone,M.B.: Detection of human cytomegalovirus in peripheral blood lymphocytes in a natural infection. Science 230, 1048 (1985).

5. Stannier,P., Taylor,D.L., Kitchen,A.D., Wales,N., Tryhorn,Y., Tyms,A.S.: Persistence of cytomegalovirus in mononuclear cells in peripheral blood from blood donors. BMJ 299, 897 (1989).

6. Sinclair,J., Sissons,P.: Latent and persistent infections of monocytes and macrophages. Intervirology 39 , 293 (1996).

7. Danker,W.M., McCutcheon,J.A., Richman,D.D., Hirata,K., Spector,S.A.: Localization of human cytomegalovirus in peripheral blood leukocytes by in situ hybridization. J Infect Dis 161, 31 (1990). 
8. Jiwa,N.M., Van Gemert,G.W., Raap,A.K., Van de Rijke,F.M., Mulder,A., Lens,P.F., Salimans,M.M., Zwaan,F.E., Van Dorp,W., Van der Ploeg,M.: Rapid detection of human cytomegalovirus DNA in peripheral blood leukocytes of viraemic transplant recipients by the polymerase chain reaction. Transplantation 48, 72 (1989).

9. Grefte,J.M., van der Gun,B.T., Schmolke,S., van der Giessen,M., van Son,W.J., Plachter,B., Jahn,G., The TH: The lower matrix protein pp65 is the principal viral antigen present in peripheral blood leukocytes during an active cytomegalovirus infection. J Gen Virol 73, 2923 (1992).

10. Fox,J.C., Griffiths,P.D., Emery,V.C.: Quantification of human cytomegalovirus DNA using the polymerase chain reaction. J Gen Virol 73, 2405 (1992).

11. Golzan,J., Laporte,G.P., Lesage,S., Labopin,M., Najman,A., Gorin,N.C., Petit,J.C.: Monitoring of cytomegalovirus infection and disease in bone marrow recipients by reverse transcription PCR and comparison with PCR and blood and urine cultures. J Clin Microbiol 34, 2085 (1996).

12. Barrett Muir,W.Y., Aitken,C., Templeton,K., Raftery,M., Kelsey,S.M., BreuerJ.: Evaluation of the Murex Hybrid Capture cytomegalovirus DNA assay versus plasma PCR and shell vial assay for diagnosis of human cytomegalovirus viraemia in immunocompromised patients. J Clin Microbiol 36, 2554 (1998).

13. Chung,C.T., Miller,R.H.: A rapid and convenient method for the preparation and storage of competent bacterial cells. Nucleic Acids Research 16, 3580 (1988). 